Advances in Intelligent Systems and Computing 794

Tareq Z. Ahram · Christianne Falcão Editors

Advances in Usability,

User Experience and

Assistive Technology

Proceedings of the AHFE 2018

International Conferences on Usability

\& User Experience and Human Factors

and Assistive Technology, Held on July

21-25, 2018, in Loews Sapphire Falls

Resort at Universal Studios, Orlando,

Florida, USA 


\section{Advances in Intelligent Systems and Computing}

Volume 794

Series editor

Janusz Kacprzyk, Polish Academy of Sciences, Warsaw, Poland

e-mail: kacprzyk@ibspan.waw.pl 
The series "Advances in Intelligent Systems and Computing" contains publications on theory, applications, and design methods of Intelligent Systems and Intelligent Computing. Virtually all disciplines such as engineering, natural sciences, computer and information science, ICT, economics, business, e-commerce, environment, healthcare, life science are covered. The list of topics spans all the areas of modern intelligent systems and computing such as: computational intelligence, soft computing including neural networks, fuzzy systems, evolutionary computing and the fusion of these paradigms, social intelligence, ambient intelligence, computational neuroscience, artificial life, virtual worlds and society, cognitive science and systems, Perception and Vision, DNA and immune based systems, self-organizing and adaptive systems, e-Learning and teaching, human-centered and human-centric computing, recommender systems, intelligent control, robotics and mechatronics including human-machine teaming, knowledge-based paradigms, learning paradigms, machine ethics, intelligent data analysis, knowledge management, intelligent agents, intelligent decision making and support, intelligent network security, trust management, interactive entertainment, Web intelligence and multimedia.

The publications within "Advances in Intelligent Systems and Computing" are primarily proceedings of important conferences, symposia and congresses. They cover significant recent developments in the field, both of a foundational and applicable character. An important characteristic feature of the series is the short publication time and world-wide distribution. This permits a rapid and broad dissemination of research results.

\section{Advisory Board}

\section{Chairman}

Nikhil R. Pal, Indian Statistical Institute, Kolkata, India

e-mail: nikhil@isical.ac.in

Members

Rafael Bello Perez, Universidad Central "Marta Abreu" de Las Villas, Santa Clara, Cuba

e-mail: rbellop@uclv.edu.cu

Emilio S. Corchado, University of Salamanca, Salamanca, Spain

e-mail: escorchado@usal.es

Hani Hagras, University of Essex, Colchester, UK

e-mail: hani@essex.ac.uk

László T. Kóczy, Széchenyi István University, Győr, Hungary

e-mail: koczy@sze.hu

Vladik Kreinovich, University of Texas at El Paso, El Paso, USA

e-mail:vladik@utep.edu

Chin-Teng Lin, National Chiao Tung University, Hsinchu, Taiwan

e-mail: ctlin@mail.nctu.edu.tw

Jie Lu, University of Technology, Sydney, Australia

e-mail: Jie.Lu@uts.edu.au

Patricia Melin, Tijuana Institute of Technology, Tijuana, Mexico

e-mail: epmelin@hafsamx.org

Nadia Nedjah, State University of Rio de Janeiro, Rio de Janeiro, Brazil

e-mail: nadia@eng.uerj.br

Ngoc Thanh Nguyen, Wroclaw University of Technology, Wroclaw, Poland

e-mail: Ngoc-Thanh.Nguyen@pwr.edu.pl

Jun Wang, The Chinese University of Hong Kong, Shatin, Hong Kong

e-mail: jwang @mae.cuhk.edu.hk

More information about this series at http://www.springer.com/series/11156 
Tareq Z. Ahram · Christianne Falcão

Editors

\section{Advances in Usability, User Experience and Assistive Technology}

Proceedings of the AHFE 2018 International Conferences on Usability \& User Experience and Human Factors and Assistive Technology, Held on July 21-25, 2018, in Loews Sapphire Falls Resort at Universal Studios, Orlando, Florida, USA

\section{黛 Springer}




\section{Editors}

\author{
Tareq Z. Ahram \\ University of Central Florida \\ Orlando, FL, USA
}

\author{
Christianne Falcão \\ Catholic University of Pernambuco \\ Boa Viagem, Pernambuco, Brazil
}

ISSN 2194-5357

ISSN 2194-5365 (electronic)

Advances in Intelligent Systems and Computing

ISBN 978-3-319-94946-8 ISBN 978-3-319-94947-5 (eBook)

https://doi.org/10.1007/978-3-319-94947-5

Library of Congress Control Number: 2018947439

(C) Springer International Publishing AG, part of Springer Nature 2019

This work is subject to copyright. All rights are reserved by the Publisher, whether the whole or part of the material is concerned, specifically the rights of translation, reprinting, reuse of illustrations, recitation, broadcasting, reproduction on microfilms or in any other physical way, and transmission or information storage and retrieval, electronic adaptation, computer software, or by similar or dissimilar methodology now known or hereafter developed.

The use of general descriptive names, registered names, trademarks, service marks, etc. in this publication does not imply, even in the absence of a specific statement, that such names are exempt from the relevant protective laws and regulations and therefore free for general use.

The publisher, the authors, and the editors are safe to assume that the advice and information in this book are believed to be true and accurate at the date of publication. Neither the publisher nor the authors or the editors give a warranty, express or implied, with respect to the material contained herein or for any errors or omissions that may have been made. The publisher remains neutral with regard to jurisdictional claims in published maps and institutional affiliations.

Printed on acid-free paper

This Springer imprint is published by the registered company Springer International Publishing AG part of Springer Nature

The registered company address is: Gewerbestrasse 11, 6330 Cham, Switzerland 


\section{Advances in Human Factors and Ergonomics 2018}

\section{AHFE 2018 Series Editors}

Tareq Z. Ahram, Florida, USA

Waldemar Karwowski, Florida, USA

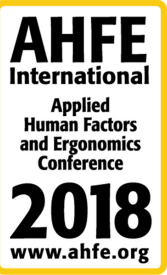

\section{9th International Conference on Applied Human Factors and Ergonomics and the Affiliated Conferences}

Proceedings of the AHFE 2018 International Conference on Usability \& User Experience and Human Factors and Assistive Technology, Held on July 21-25, 2018, in Loews Sapphire Falls Resort at Universal Studios, Orlando, Florida, USA

\begin{tabular}{|c|c|}
\hline Advances in Affective and Pleasurable Design & Shuichi Fukuda \\
\hline $\begin{array}{l}\text { Advances in Neuroergonomics } \\
\text { and Cognitive Engineering }\end{array}$ & Hasan Ayaz and Lukasz. Mazur \\
\hline Advances in Design for Inclusion & Giuseppe Di Bucchianico \\
\hline Advances in Ergonomics in Design & $\begin{array}{l}\text { Francisco Rebelo and Marcelo } M . \\
\text { Soares }\end{array}$ \\
\hline $\begin{array}{l}\text { Advances in Human Error, Reliability, Resilience, } \\
\text { and Performance }\end{array}$ & Ronald L. Boring \\
\hline $\begin{array}{l}\text { Advances in Human Factors and Ergonomics in } \\
\text { Healthcare and Medical Devices }\end{array}$ & Nancy J. Lightner \\
\hline $\begin{array}{l}\text { Advances in Human Factors in Simulation } \\
\text { and Modeling }\end{array}$ & Daniel N. Cassenti \\
\hline $\begin{array}{l}\text { Advances in Human Factors and Systems } \\
\text { Interaction }\end{array}$ & Isabel L. Nunes \\
\hline Advances in Human Factors in Cybersecurity & Tareq Z. Ahram and Denise Nicholson \\
\hline $\begin{array}{l}\text { Advances in Human Factors, Business } \\
\text { Management and Society }\end{array}$ & $\begin{array}{l}\text { Jussi Ilari Kantola, Salman Nazir } \\
\text { and Tibor Barath }\end{array}$ \\
\hline $\begin{array}{l}\text { Advances in Human Factors in Robots } \\
\text { and Unmanned Systems }\end{array}$ & Jessie Chen \\
\hline $\begin{array}{l}\text { Advances in Human Factors in Training, } \\
\text { Education, and Learning Sciences }\end{array}$ & $\begin{array}{l}\text { Salman Nazir, Anna-Maria Teperi } \\
\text { and Aleksandra Polak-Sopińska }\end{array}$ \\
\hline Advances in Human Aspects of Transportation & Neville Stanton \\
\hline
\end{tabular}


(continued)

\begin{tabular}{l|l}
\hline $\begin{array}{l}\text { Advances in Artificial Intelligence, Software } \\
\text { and Systems Engineering }\end{array}$ & Tareq Z. Ahram \\
\hline $\begin{array}{l}\text { Advances in Human Factors, Sustainable Urban } \\
\text { Planning and Infrastructure }\end{array}$ & $\begin{array}{l}\text { Jerzy Charytonowicz and Christianne } \\
\text { Falcão }\end{array}$ \\
\hline $\begin{array}{l}\text { Advances in Physical Ergonomics \& Human } \\
\text { Factors }\end{array}$ & $\begin{array}{l}\text { Ravindra S. Goonetilleke and Waldemar } \\
\text { Karwowski }\end{array}$ \\
\hline $\begin{array}{l}\text { Advances in Interdisciplinary Practice in } \\
\text { Industrial Design }\end{array}$ & WonJoon Chung and Cliff Sungsoo Shin \\
\hline $\begin{array}{l}\text { Advances in Safety Management and Human } \\
\text { Factors }\end{array}$ & Pedro Miguel Ferreira Martins Arezes \\
\hline Advances in Social and Occupational Ergonomics & Richard H. M. Goossens \\
\hline $\begin{array}{l}\text { Advances in Manufacturing, Production } \\
\text { Management and Process Control }\end{array}$ & $\begin{array}{l}\text { Waldemar Karwowski, Stefan } \\
\text { Trzcielinski, Beata Mrugalska, Massimo } \\
\text { Di Nicolantonio and Emilio Rossi }\end{array}$ \\
\hline $\begin{array}{l}\text { Advances in Usability, User Experience } \\
\text { and Assistive Technology }\end{array}$ & Tareq Z. Ahram and Christianne Falcão \\
\hline $\begin{array}{l}\text { Advances in Human Factors in Wearable } \\
\text { Technologies and Game Design }\end{array}$ & Tareq Z. Ahram \\
\hline $\begin{array}{l}\text { Advances in Human Factors in Communication } \\
\text { of } \text { Design }\end{array}$ & Amic Ho \\
\hline
\end{tabular}




\section{Preface}

Successful interaction with products, tools, and technologies depends on usable designs and accommodating the needs of potential users without requiring costly training. In this context, this book is concerned with emerging ergonomics in design concepts, theories, and applications of human factors' knowledge focusing on the discovery, design, and understanding of human interaction and usability issues with products and systems for their improvement.

The Human Factors and Assistive Technology promotes the exchange of ideas and techniques which enable humans to communicate and interact with each other in almost every aspect. The new relationship between humans and technology added convenience for many, and for those with impairments, modern-day technology has transformed their daily living into a journey toward capability instead of disability. Assistive technology assessment focuses on the examination of problems in designing and providing assistive devices and services to individuals with disabilities or impairment, to assist mobility, communication, positioning, environmental control, and daily living. The conference addresses a wide spectrum of theoretical and practical topics related to assistive technologies. It provides an excellent forum for combining real experience and academic research, while examining how we can adapt to machinery and increase the technology acceptance, effectiveness, and efficiency. The conference aims at investigating how psychological factors can affect the efficiency and acceptability of assistive technology.

This book will be of special value to a large variety of professionals, researchers, and students in the broad field of human modeling and performance, who are interested in feedback of devices' interfaces (visual and haptic), user-centered design, and design for special populations, particularly the elderly. We hope this book is informative, but even more that it is thought-provoking. We hope it inspires, leading the reader to contemplate other questions, applications, and 
potential solutions in creating good designs for all. The book is organized into nine sections that focus on the following subject matters:

Section 1: UX Evaluation and Design Thinking

Section 2: Human Machine Interfaces

Section 3: Usability Evaluation and User-Centered Design

Section 4: Virtual Reality and Interaction Design

Section 5: User Experience in Healthcare and Learning

Section 6: User Experience and Visualization in Automotive Industry

Section 7: Eye Tracking and Visualization

Section 8: Assistive Technology and Design Solutions

Section 9: Assistive Design Solutions and Prosthetic Environments

This book will be of special value to a large variety of professionals, researchers, and students in the broad field of human-computer interaction, usability engineering, and user experience research, who are interested in feedback of devices' interfaces (visual and haptic), user-centered design, and design for special populations, particularly the elderly.

Each section contains research papers that have been reviewed by members of the International Editorial Board. Our sincere thanks and appreciation to the board members as listed below:

\section{Usability \& User Experience}

Hanan A. Alnizami, USA

Wolfgang Friesdorf, Germany

S. Fukuzumi, Japan

Sue Hignett, UK

Wonil Hwang, South Korea

Yong Gu Ji, South Korea

Bernard C. Jiang, Taiwan

Ger Joyce, UK

Chee Weng Khong, Malaysia

Zhizhong Li, PR China

Nelson Matias, Brazil

Abbas Moallem, USA

Beata Mrugalska, Poland

Francisco Rebelo, Portugal

Valerie Rice, USA

Emilio Rossi, Italy

Javed Anjum Sheikh, Pakistan

Alvin Yeo, Malaysia

Wei Zhang, PR China 


\section{Assistive Technology}

Hanan A. Alnizami, USA

Wolfgang Friesdorf, Germany

S. Fukuzumi, Japan

Sue Hignett, UK

Matteo Zallio, Ireland

We hope this book is informative, but even more thought provoking to inspire the reader to contemplate other questions, applications, and potential solutions in creating good designs for all.

July 2018

Tareq Z. Ahram Christianne Soares Falcão 


\section{Contents}

\section{UX Evaluation and Design Thinking}

Idealization Effects in UX Evaluation at Early Concept Stages:

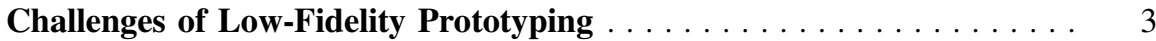

Lara Christoforakos and Sarah Diefenbach

Heuristic Evaluation for Mobile Applications: Extending

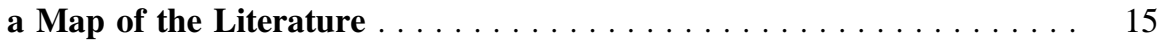

Ger Joyce, Mariana Lilley, Trevor Barker, and Amanda Jefferies

Empirical Study on the Documentation Phase

in the Human-Centered Design Process . . . . . . . . . . . . . . . . 27

Gabriela Viana, Dory Azar, and Kristin Morin

In Search of the User's Language: Natural Language Processing,

Computational Ethnography, and Error-Tolerant Interface Design . . . . 36

Timothy Arnold and Helen J. A. Fuller

Disrespectful Technologies: Social Norm Conflicts in Digital Worlds . . . 44

Sarah Diefenbach and Daniel Ullrich

The Effects of Icon Characteristics on Search Time . . . . . . . . . . . 57

Mick Smythwood and Mirsad Hadzikadic

The Limited Rationale in Decision Making, Impacts on the Evaluation

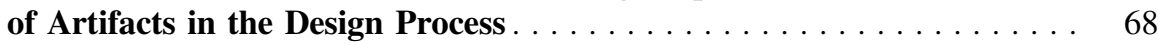

Walquir Fernandes, Walter Correia, and Fabio Campos

Usability Heuristics for M-Commerce Apps . . . . . . . . . . . . . . . . 79

Samar I. Swaid and Taima Z. Suid

Usability and Design Guideline for Designing Single Handle

Faucet's and Handle Shape

Riku Takagi, Noriko Hashida, and Hiroyuki Takeuchi 
A Comparative Study of Product Usability and Ergonomic

Assessment of Server Lifts . . . . . . . . . . . . . . . . . . . . . . . . . . . 99

Dosun Shin

User Evaluation of MyStudentScope: A Web Portal for Parental

Management of Their Children's Educational Information

Theresa Matthews, Ying Zheng, Zhijiang Chen, and Jinjuan Heidi Feng

Usability Evaluation of a State University Grade Encoding System . . . 122

John Paolo Isip and Hazel Caparas

How to Get to Know Your Customers Better? A Case

Analysis of Smartphone Users with Chinese Input Method

Based on Baidu Index

Wenchao Zuo, Yuhong Wang, and Yueqing Li

\section{Human Machine Interfaces}

Determining the Effect of Training on Uncertainty

Visualization Evaluations

Stephen M. Fiore, Jihye Song, Olivia B. Newton, Corey Pittman,

Samantha F. Warta, and Joseph J. LaViola

Adaptive Control Elements to Improve the HMI

of an Agricultural Tractor .

Timo Schempp, Andreas Kaufmann, Ingmar Stoehr, Markus Schmid, and Stefan Boettinger

Research on Interface Design of Full Windshield Head-Up Display

Based on User Experience

Ting Deng, Wei Sun, Ruiqiu Zhang, and Yu Zhang

Study on Human-Computer Interaction in the Design of Public

Self-service Equipment

Huaming Peng, Shuxian Liu, and Tengfei Zhang

Evaluating the Usability of a Head-Up Display While Driving

a Vehicle

Guilherme Gattás Bara, Patrícia Caetano Bara, José Castanõn,

and Maria Teresa Barbosa

Usability Evaluation and User-Centered Design

Getting the Complete Picture: Using Surveys as a Complementary

Method for Assessing Usability

Courtney Titus, Mary Gordon, Krisanne Graves, and Curt Braun 
The Effects of Grid- and List Design of E-Commerce Result Lists on Search Efficiency and Perceived Aesthetics . . . . . . . . . . . . . . . . . . 204 Friederice Schröder, Anica Kleinjan, and Stefan Brandenburg vis-UI-lise: Developing a Tool for Assessing User Interface Visibility . . . 212 Ian Hosking and P. John Clarkson

An Investigation of Key Factors Influencing Aircraft

Comfort Experience . . . . . . . . . . . . . . . . . . . . . . . . . . 222

Wenhua Li, Jianjie Chu, Bingchen Gou, and Hui Wang

UX Evaluation of a New Rowing Ergometer: The Case Study of the Technogym "SkillRow"

Alessia Brischetto, Mattia Pistolesi, Giuseppe Fedele, and Francesca Tosi

Neck Flexion Angle and User Experience Compared on iPhone X and Samsung S8+.

Saishyam Akurke and Yueqing Li

User Skill Characteristics Analysis by Mouse Operation Log Analysis Based on Algebraic Method

Takeshi Matsuda, Michio Sonoda, Masasi Eto, Hironobu Satoh,

Tomohiro Hanada, Nobuhiro Kanahama, and Hiroki Ishikawa

Estimation of the Smartphone User' Satisfaction and Customer

Intention on the Social Networking Service

Young-Hee Lee and Ryang-Hee Kim

Adding Eye Tracking Data Collection to Smartphone Usability

Evaluation: A Comparison Between Eye Tracking Processes

and Traditional Techniques

Marcos Souza and Fracimar Maciel

Usability Evaluation of Self-service Laundry System in Universities . . . 283 Meiyu Zhou, Chao Li, and Can Zhao

Agile Project Management: Better Deliveries to the End User in Software Projects with a Management Model by Scrum

Hugo Almeida and Walter Correia

The Contribution of Design in the Waiting Experience of Applicants

to Parents in the Process of Adoption in Recife . . . . . . . . . . . . . . . 306

Haidée Cristina Câmara Lima, Walquíria Castelo Branco Lins, José Carlos Porto Arcoverde, Jr., and Walter Franklin Marques Correia

Difference of Sensitiveness Toward Information Based on User-Role . . 318 Yeongchae Choi and Weonseok Yang 
Improvement Method for Business Operations Using

User Experience Adaptive Information Sharing Terminals

Yuka Sugiyama, Toshikazu Kato, and Takashi Sakamoto

Research on the Model Construction of Intelligent Home Product

Service Based on User Value

Weiwei Wang, Yunyan Zhang, and Ting Wei

The Effects of Response Time on User Perception in Smartphone

Interaction

Zhengyu Tan, Jieru Zhu, Jun Chen, and Fusheng Li

User's Behavior Under Review: The Use of Instrument's

to Evaluate Perception of Users

Marina Barros, Walter Correia, and Fabio Campos

A Study on Determining the Heuristics for Evaluating the Usability of Hot Drink Preparation Devices by Elderly Users . . . . . . . . . . . . . . 362

Aybegum Numanoglu and Cem Alppay

Comparative Study on Reading Performance of Different Electronic

Ink Screens

Yuan Lyu, Yunhong Zhang, Wei Li, Zhongting Wang, and Lou Ding

Research on Interactive Innovation Design of Barrier-Free Products for Visually Impaired Groups

Zijie Xie

Harnessing Music to Enhance Speech Recognition

Vered Aharonson, Shany Mualem, and Eran Aharonson

Usability Study and Redesign of the Food Tray .

Kimberly Anne Sheen, Yan Luximon, Kar Hei Fung, Shun Him Chak,

Wai Yi Chiu, and Wing Sang Chan

Evaluation of Aesthetic and Emotional Satisfaction of Mobile

Phone Users

Young-Hee Lee and Ryang-Hee Kim

Research on the Optimization Method of Website Based

on User Experience

Chun-Fu Li and Ya-Qi Jiang

Research on Shared Product Design Based on Service Design

Concept-Illustrated by the Case of "Ofo" Design

Qian Ji, Jiayu Zheng, and Yu Zhang

Preferred Height and Angle of Touch Screen

Yahui Bai, Yinxia Li, Huimin $\mathrm{Hu}, \mathrm{Na}$ Lin, Haimei Wu, and Pu Hong 
Design of Proton Therapy Procedure Based on Service

Design Theory

Xinxiong Liu and Wanru Wang

Usability Recommendations for a Learning Management Systems

(LMS) - A Case Study with the LMS of IFPE

Marcelo Penha and Walter Franklin Marques Correia

User Experience Design Manifesto . . . . . . . . . . . . . . . . . . . . . . . 461

Paulo Maldonado

The Development of a Hybrid Approach to Usability Assessment:

Leveraging a Heuristic Guidance Framework for End

User Feedback

Beth F. Wheeler Atkinson, Mitchell J. Tindall, and Emily C. Anania

A Pilot Naturalistic Study of PC Mouse Usability

Denis A. Coelho and Miguel L. Lourenço

Appropriate Operating Force of Knob in Certain Conditions

Huimin $\mathrm{Hu}$, Pu Hong, Aiping Yang, Hong Luo, Yahui Bai,

and Yinxia $\mathrm{Li}$

Study on the Handle Test Sample of Furniture for Ergonomics

Experiment . . . . . . . . . . . . . . . . . . . . . . . . . . . . . . . 504

Zhiyu Xu, $\mathrm{Na} \mathrm{Yu,} \mathrm{Huimin} \mathrm{Hu}$, Yahui Bai, and Pu Hong

Research on the Standard of Refrigerator Noise Quality Evaluation . . 516 Xin Zhang, Shuiyuan Yu, Linghua Ran, and Huimin $\mathrm{Hu}$

The Interface Design of Mobile Library: A Case Study . . . . . . . . . . . 525

Siyu Yang, Peng An, and Zhe Chen

Design of Location-Based Audio Guide System for City Tourism . . . . 535

Shiori Furuta and Katsuhiko Ogawa

\#MeToo: An App to Enhancing Women Safety . . . . . . . . . . . . . . . . 546

Javed Anjum Sheikh and Zonia Fayyaz

Seeing Patterns for Guiding Users and Avoiding Pitfalls

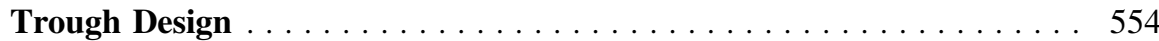

Tingyi S. Lin

Usability and Interaction Evaluation on Breakfast Delivery Mobile

App: Users' Experience Expectations . . . . . . . . . . . . . . . . . . . . . . . . . . 564

Marcelo A. Guimarães and Adriano B. Renzi

Automated Smartphone Keyboard Error Corrections . . . . . . . . . . . . . 574

Vered Aharonson, Rotem Rousseau, and Eran Aharonson 
Virtual Reality and Interaction Design

In the Journey of User Center Design for the Virtual Environment . . 583 Norma Antunano

Analysis of the Relationship Between Content and Interaction in the Usability Design of $360^{\circ}$ Videos

Nicholas Caporusso, Meng Ding, Matthew Clarke, Gordon Carlson, Vitoantonio Bevilacqua, and Gianpaolo Francesco Trotta

Evaluation of Usability and Workload Associated with Paper Strips as Compared to Virtual Flight Strips Used for Ramp Operations Victoria Dulchinos

The Development of an Online Questionnaire for End Users About the Visual Perception of Informational Ergonomics and Its Attributes in Graphic Brands . . . . . . . . . . . . . . . . . . . . . . . . . . . . . . . . . 615 João Carlos Riccó Plácido da Silva, Luis Carlos Paschoarelli, Valéria Ramos Friso, and José Carlos Plácido da Silva

Accessibility in Chatbots: The State of the Art in Favor of Users with Visual Impairment

Cecília Torres, Walter Franklin, and Laura Martins

User Experience in Healthcare and Learning

Usability Assessment of a Portable Corneal Topography Device

Carlos Aceves-González, Zuli T. Galindo-Estupiñan, Irma C. Landa-Avila,

Citlali Díaz-Gutiérrez, and Stephanie Daphne Prado-Jiménez

Designing and Developing a Prototype of Parents and Teachers

Communication Application for Early Childhood

Manutchanok Jongprasithporn, Nantakrit Yodpijit, Kristin Halligan, and Teppakorn Sittiwanchai

Research on User Comfort of Intelligent Toilet Based on Ergonomics

Zhongting Wang, Haimei Wu, Wang Wei, Ling Luo, Yunhong Zhang, and Chaoyi Zhao

Satisfaction Analysis for Using Educational Serious Games for Teaching Wound Treatment.

Gabriel Candido da Silva, Lúcia Paloma Freitas da Silva, Nicolau Calado Jofilsan, Walter Franklin M. Correia, Alex Sandro Gomes, and Amadeu S. Campos Filho

Development and Experiential Analysis of a Chinese Customer Satisfaction Model for Medical Service Industry

Ruifeng Yu, Jacky Y. K. Ng, Alan H. S. Chan, and Yifan Tian 
User Experience and Visualization in Automotive Industry

Drivers Quickly Trust Autonomous Cars .

Robert Broström, Annie Rydström, and Christoffer Kopp

Scenario-Based User Experience Research in Automobile Interior

Lighting Innovation 706

Bo Ouyang and Yun He

Usability Research of In-vehicle 3D Interactive Gestures

Hao Tan and Qin Zhang

\section{Eye Tracking and Visualization}

Application of Eye Tracking Technology in Naturalistic Usability Assessment of an Academic Library Website . . . . . . . . . . . . . .

Nima Ahmadi, Matthew R. Romoser, Lindsay M. Guarnieri, Theresa G. Kry, and Emily I. Porter-Fyke

Log-Based Process Visualization

Johannes Schwank, Sebastian Schöffel, and Achim Ebert

Bullet Graph Versus Gauges Graph: Evaluation Human

Information Processing of Industrial Visualization Based

on Eye-Tracking Methods

Lei Wu, Lingli Guo, Hao Fang, and Lijun Mou

Effectiveness of Eye-Gaze Input Method: Comparison of Speed and Accuracy Among Three Eye-Gaze Input Method 763 Atsuo Murata and Makoto Moriwaka

Assistive Technology and Design Solutions

A Digital Assistance System Providing Step-by-Step Support

for People with Disabilities in Production Tasks . . . . . . . . . . . . . . 775

Volkan Aksu, Sascha Jenderny, Björn Kroll, and Carsten Röcker

My Intelligent Home (MiiHome) Project 786

Ipek Caliskanelli, Samia Nefti-Meziani, Jonathan Drake, and Anthony Hodgson

Co-designing: Working with Braille Users in the Design of a Device to Teach Braille . . . . . . . . . . . . . . . . . . . . . . . 798 Rhianne M. Lopez, Shane D. Pinder, and T. Claire Davies

Reducing Scanning Keyboard Input Errors with Extended Start Dwell-Time . . . . . . . . . . . . . . . . . . . . . . . . . . 808 Frode Eika Sandnes, Evelyn Eika, and Fausto Orsi Medola 
Variations in Vital Signs Associated with the Postural Changes When Using a Stand-up Wheelchair in Patients with Spinal Cord Injury

Thalía San Antonio, Fernando Urrutia, Anita Larrea, Víctor Espín, and María Augusta Latta

We Have Built It, But They Have Not Come: Examining the Adoption and Use of Assistive Technologies for Informal Family Caregivers . . . . . . . . . . . . . . . . . . . . . . . . . . 824

Pamela Wisniewski, Celia Linton, Aditi Chokshi, Brielle Perlingieri, Varadraj Gurupur, and Meghan Gabriel

Touchscreen-Based Haptic Information Access for Assisting Blind and Visually-Impaired Users: Perceptual Parameters and Design Guidelines

Hari Prasath Palani, Jennifer L. Tennison, G. Bernard Giudice, and Nicholas A. Giudice

Towards a Macroscopic View of Using an Assistive Technology for Mobility for Its Development: Assessing Users' and Co-users' Experience 848 Anne-Marie Hébert, Philippe Archambault, and Dahlia Kairy

Digitalize Limits for Increased Capability: Technology to Overcome Human Mechanisms 860

Mila Stepanovic and Venere Ferraro

Modeling Augmentative Communication with Amazon Lex and Polly

Ahmad Abualsamid and Charles E. Hughes

An Age Adapting Electrolarynx - A Feasibility Study

Pieter Coetzee, Joice Lamfel, David M. Rubin, and Vered Aharonson

Designing and Creating a Prototype of Robotic Skeleton Systems for Computerized Lower Limb Prosthesis

Yatip Auarmorn, Nantakrit Yodpijit, and Manutchanok Jongprasithporn

Interdisciplinary-Based Development of User-Friendly Customized 3D Printed Upper Limb Prosthesis.

Letícia Alcará da Silva, Fausto Orsi Medola, Osmar Vicente Rodrigues, Ana Cláudia Tavares Rodrigues, and Frode Eika Sandnes

A Software Based on Eye Gaze to Evaluate Mathematics in Children with Cerebral Palsy in Inclusive Education

Omar Alvarado-Cando, G. Belén Jara, Paúl Barzallo, and Hugo Torres-Salamea 
Research on the Environmental Thermal Comfort Based

on Manikin.

Rui Wang, Chaoyi Zhao, Huimin Hu, Yifen Qiu, and Xueliang Cheng

Specific Dyslexia Exploratory Test (TEDE): Two Tasks Using

Augmented Reality .

Maritzol Tenemaza, Rosa Navarrete, Erika Jaramillo,

and Andrés Rodriguez

Mobile Application for Crowdmapping Accessibility Places

and Generation of Accessible Routes

Nigel da Silva Lima, João Pedro Caldas Leite, Anselmo Cardoso de Paiva,

Ivana Marcia Oliveira Maia, Aristófanes Corrêa Silva,

Geraldo Braz Junior, and Cláudio de Souza Baptista

Development of a Tracking Sound Game System for Exercise

Support of the Visually Impaired Using Kinect .

Kazuki Miyamoto, Kodai Ito, and Michiko Ohkura

Assistive Design Solutions and Prosthetic Environments

Empowering Design Solutions for Orbital Epitheses, Avoiding

the Uncanny Valley

Julie Snykers, Yvonne Motzkus, Marieke Van Camp, and Kristof Vaes

Examining Visually Impaired People's Embossed Dots Graphics

with a 3D Printer: Physical Measurements and Tactile

Observation Assessments

Kazunori Minatani

Workplace Accommodation for Autistics: Autistic Autobiography

and Technology-Enabled Prosthetic Environments . . . . . . . . . . . . . 970

G. R. Scott

Biomechanical Models of Computerized Prosthetic Leg .

Nantakrit Yodpijit, Manutchanok Jongprasithporn, Penpetch Maneewong,

Nanthanit Faksang, and Teppakorn Sittiwanchai

Human-Centered Design of Computerized Prosthetic Leg:

A Questionnaire Survey for User Needs Assessment

Nantakrit Yodpijit, Manutchanok Jongprasithporn, Uttapon Khawnuan,

Teppakorn Sittiwanchai, and Juthamas Siriwatsopon

Enhancing Voice Quality in Vocal Tract Rehabilitation Device 1006

Bianca Sutcliffe, Lindzi Wiggins, David M. Rubin, and Vered Aharonson

Author Index 


\title{
UX Evaluation of a New Rowing Ergometer: The Case Study of the Technogym "SkillRow"
}

\author{
Alessia Brischetto $^{1(\bowtie)}$, Mattia Pistolesi ${ }^{1}$, Giuseppe Fedele ${ }^{2}$, \\ and Francesca Tosi ${ }^{1}$ \\ ${ }^{1}$ Laboratory of Ergonomics and Design, Department of Architecture,
} University of Florence, Via Sandro Pertini 93, 50041 Florence, Calenzano, Italy

\{alessia.brischetto, mattia.pistolesi, francesca.tosi\}@unifi.it

2 Scientific Research Department, Technogym S.P.A, Via Calcinaro, 2861, 47521 Cesena, Italy

\begin{abstract}
This paper demonstrates the results of workshop "UX Skillrow Evaluation" workshop, promoted by the Laboratory of Ergonomics and Design (LED) of the University of Florence in collaboration with Technogym, a leading-edge company that develops fitness equipment for any physical activity. The workshop aimed to define the current levels of usability and experience of use of rowing "Skillrow", through method of investigation and practice of Human-Centered Design and User Experience approaches. The predominant aim of work was to identify usability and user experience of rowing Skillrow and its user interfaces. Following this, to identify the potential, project proposals were conducted, brainstorming and focus group activities. During testing twenty-one users participated, aged between 22 and 30. The research goals were: measurements of current usability level and user experience of productsystem interfaces, and definition of critical issues and implementation of the current user interfaces. Finally, the results from the evaluation phases allowed to get qualitative data on the levels of effective usability of the product, the components and its graphic interface. In the form of scenario-based design, solutions to improve the current high levels of usability of the user interface were also developed.
\end{abstract}

Keywords: Wellness $\cdot$ Human-Centered Design $\cdot$ User Experience User Observation · Focus group

\section{Introduction}

Human beings were not born for inactivity. Physical inactivity is nowadays identified as the fourth leading risk factor for global mortality and its levels are rising in many countries. This phenomenon has major implications for the prevalence of no communicable disease (NCDs) and the general health of the population worldwide [1]. On the contrary, movement and physical activity contribute to improving all aspects of quality of life, representing a strategic tool for healthy aging [2].

It is therefore necessary to educate as many people as possible to an active lifestyle even at an advanced age. In order to do so, it is important to develop high added-value 
products for the wellbeing and health of people, and this goal can be achieved through an interdisciplinary approach between Design and Ergonomics [3].

Within the fitness industry one of the most complete UX markets in emerging, in the form of a gym or personal fitness environment. A new paradigm known as "smart gyms" are aimed at providing support for both the trainers and users, keeping track of all activity and later tailoring the experience to the direct specifications of the individual. The growth and development in digital technology has been expansive, assisting all individuals throughout a training session in addition to providing a more engaging and interactive experience. The advances of touch screen display not only offer information (requiring input) specific to the exercise however have additional features to allow a more connected experience with the digital ecosystem such a social networking and personalized multimedia content, making these tools particularly more interesting to the HF/E community. Unfortunately however, although there is a great increased interest in mobile technologies within fitness a cursory literature search identifies that the interest of technology within the fitness environment is directed towards the hardware components demonstrating a greater significance on biomechanics and ergonomics with reference to comfort and safety [4-6].

Additional contributions, commonly targeting the design of tools for a specific population, are rare (e.g. elderly, people with disabilities), in addition to the promotion and monitoring of physical activity.

This was the case with the "SkillRow UX evaluation" workshop, conducted and developed in collaboration with Technogym S.p.A. at the Laboratory of Ergonomics and Design (LED) of Florence University. Aim of the study was the evaluation of the overall user experience (UX) with the rowing ergometer SkillRow and the willingness to promote it.

\section{Background: Usability and User Experience}

To design an industrial product, it is fundamental knowing the specific needs of the addressed users.

The Italian standard UNI 11377-1:2010 [7] and international standard ISO 9241210:2010 [8] define usability as: "extent to which a system, product or service can be used by specified users to achieve specified goals with effectiveness, efficiency and satisfaction in a specified context of use". Nielsen defines usability as the sum of 5 attributes [9]: learnability; efficiency; memorability; errors; satisfaction. Usability is not an absolute characteristic of the object, but it is always relative to the task, the user and the environment [10].

The process of identification and needs analysis on which the Human-centered Design is based, is carried out through the realization of usability tests that may be conducted by specialist and/or the direct involvement of a segment of users representing the targeted consumers [11]. The methods of usability verifications and safe check are based on the collection of information related to the modality with which the user interact with the product within a given context of use. By doing so it is possible to identify and analyze the behavior of users, their needs and finally the type and frequency of errors performed during the execution of the required tasks. 
This information can be used to define the characteristics of the new product, to test prototypes, and/or to evaluate the existing products [11].

In regards to the User Experience, the international standard ISO 9241-210:2010 defines it as: "person's perceptions and responses resulting from the use and/or anticipated use of a product, system or service".

Whilst the usability focus on the degree to which a product can be used by specific users to achieve specific tasks with effectiveness, efficiency and satisfaction [8], the user-experience focuses on human factors such as emotional, affective and contextual aspects [12]. The evolution of this concept, as defined by ISO 9241-210:2010, takes into account that feeling positive or negative about a task can transform the user experience with the product/system [13].

\section{Workshop SkillRow UX Evaluation}

The "SkillRow UX Evaluation" workshop, organized by the University of Firenze's Ergonomic and Design Lab (LED) in partnership with Technogym SPA, had the purpose of evaluating the usability and User Experience (UX) of the "SkillRow" rowing machine. The test involved 21 subjects from various part of the World. The workshop was divided into 2 phases (phase 1 consisted of the measurement of the current usability and User Experience (UX) level of the product-interface system, while in phase 2 the criticality and margins of implementation of the current user interfaces were defined), organized in 4 days as followed:

- During the first day usability and thinking aloud tests were carried out. At the end of the session each subject submitted a user experience evaluation questionnaire;

- In regards to the second day, a brainstorming session was run, followed by a collective focus group one aimed at bringing out doubts, considerations, thoughts and difficulties encountered while interacting with the product and its components;

- During the third and fourth day, the Task Analysis, Personas and Scenario-based design methods were used in order to identify possible areas of intervention and future scenarios of use for the SkillRow.

For the evaluation of the usability level and the UX (step 1), referring to the norm ISO 9241-210:2010 [8], the following methods were selected: Questionnaire [14], Task Analysis - TA [15], User Observation [16] and Thinking aloud [17]. In regards to the to the user test sessions, a hybrid survey methodology was tested, which applied simultaneously the User Observation and the Thinking Aloud, following a heuristic approach. This approach allowed us to gather opinions, thoughts, expectations, critical points and intuitions useful for defining the requirements of the design concept. Step 2 focused on the definition of the possible areas of implementation in relation to the critical issues and needs that emerged in step 1. In this regard, the following methods were selected: Brainstorming [18] and Focus group [19], Personas [20] and Scenariobased design [21]. 


\section{Methods}

The workshop consisted of a preliminary phase which involved the analysis of the product and its components (phase 1). The results were useful for selecting the two most critical tasks that a user can face while using the rowing machine (phase 2). Once the tasks were defined, users run the test sessions. In order to increase the level of effectiveness of the analysis phase, using the tools of Thinking Aloud, each user was asked to talk loudly about the activities he was performing and the difficulties he was experiencing (phase 3). At the end of the test sessions a thematic questionnaire was submitted to each individual user (phase 4).

Once the test sessions were over, step 2 aimed to bring out needs and critical issues experienced during the tests with the rowing machine (phase 5) through brainstorming and focus groups. The last 3 phases of the workshop involved defining some possible areas of implementation and new usage scenarios in relation to the findings of phase 5; performing the Task analysis (phase 6); and using the Personas and Scenario-based design (phase 7).

\subsection{Phase 1 and 2: Preliminary Analysis and Requirements Definition}

A preliminary analysis of the product SkillRow (a) and its components SkillRow interface (b) and SkillRow app (c), was carried out by the Ergonomics and Design laboratory (LED) before proceeding to the test sessions (Fig. 1).

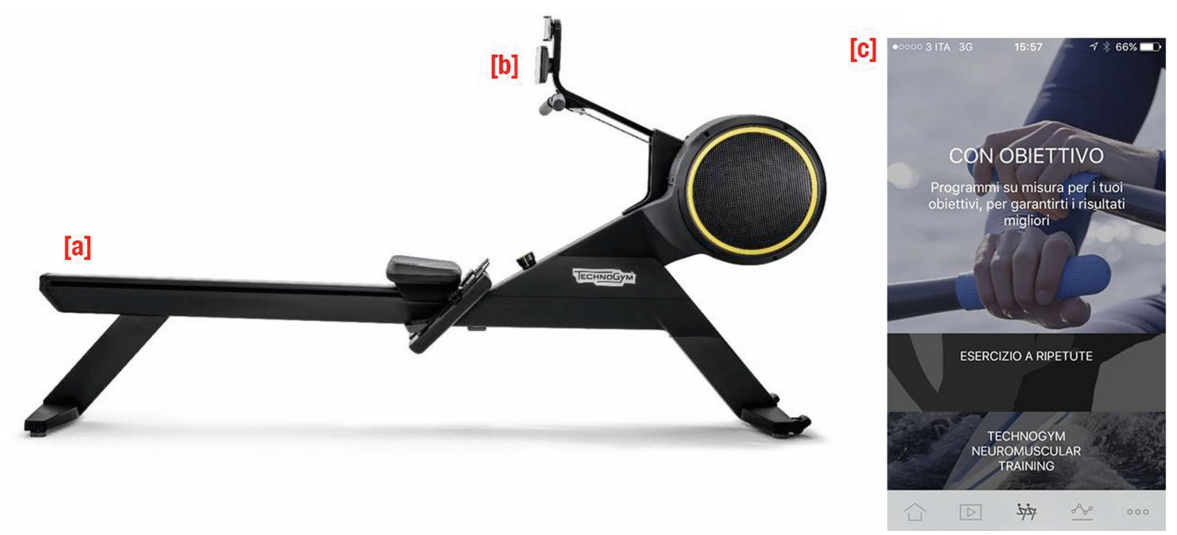

Fig. 1. The SkillRow Technogym machine and the related components

Afterwards, in collaborations with Technogym S.p.A. researchers, a recurrent task and a less recurrent one, representatives of the user experience, were identified:

- Task 1: distance training (700 m);

- Task 2: sending feedbacks to Technogym through the app. 


\subsection{Participants}

The workshop involved 21 students from the University of Firenze (13 females and 8 males) aged between 22 and 30 years. 15 from Italy, 4 from Iran, 1 from Albany, and 1 from China. In order to avoid misunderstandings, non Italian subjects had to prove to be proficient in the Italian language.

\subsection{Phase 3: Usability Test (User Observation and Thinking Aloud)}

In this phase each subject had 15 min to complete the two task mentioned above. The test was run at the Ergonomics and Design Laboratory and was mediated by two researchers from the same lab. Each session had the following rules:

- $\quad$ set the target to $700 \mathrm{~m}$ (task 1);

- starting and ending the exercise (task 1);

- sending feedback to Technogym (task 2).

During the test sessions, a hybrid survey methodology was experimented. Following a heuristic approach, the User Observation and the Thinking aloud methods were simultaneously applied. This approach made it possible to gather opinions, thoughts, expectations, critical points and intuitions useful for defining the requirements of the design concept. The User Observation allowed us to observe how users were interacting with the rowing machine. [16-22] without interfering with the normal running of the test session. To increase the level of effectiveness of the analysis phase, the Thinking Aloud method was used simultaneously with the User Observation [17]. With this method the users were invited to express loudly their thoughts, feelings and frustrations, while interacting with the machine, the problems of usability of the product were identified, and we were able to observe at the same time these interactions. The role of the researchers was to stimulate each individual to express verbally his/her thoughts [22]. After the test session, a questionnaire was submitted to each user.

\subsection{Phase 4: Questionnaire}

Once the test sessions on the SkillRow ended, each user submitted a thematic questionnaire which included biographical data, user experience (UX) and comprehension questions. The questionnaire section related to personal data and understanding included both open and closed answers [22], while the UX section was developed following the NASA TLX evaluation method. It is a multidimensional assessment tool for the subjective workload [23, 24], which allows to evaluate the users' workload while interacting with the SkillRow integrated interface, the user-SkillRow app and with the SkillRow itself. The workload, defined as the effort sustained by the user to achieve a specific level of performance [23, 24], was calculated from the result of subjective responses weighted on the following five values: (1) mental request; (2) physical request; (3) global effort; (4) performance; (5) frustration. 


\subsection{Phase 5: Brainstorming e Focus Group}

In order to highlight criticalities and needs emerged during the usability test, the participants, divided into 2 groups, were involved in the brainstorming and focus group activities, for a total duration of $4 \mathrm{~h}$. One group dealt with the SkillRow and its app for IOS, while the other group dealt with the same rower and its application for Android.

\subsection{Phase 6: Task Analysis}

The next step consisted of performing 2 Task Analysis, one for the IOS group and one for the Android group. This method allowed each group to map the possible interactions of each user with the SkillRow app interface. The Task Analysis, additionally it was necessary to identify the critical issues and consequently the possible areas of implementation.

\subsection{Phase 7: Personas and Scenario-Based Design}

The Personas and Scenario-based design techniques are fundamental tools in the design process of a product/service. The personas represent fictitious profiles created to better represent needs, aspirations and behaviors of a particular segment of users, emerged in step 5. Four Personas were defined for the Android group and four for the IOS group, for a total of eight people and eight Scenario-based design. Thanks to this technique it is possible to describe in a realistic way the actions, or the sequence of actions, that a user makes while using a specific product/service (in this case SkillRow and SkillRow app), and therefore define how they should work in order to guarantee a satisfying user experience.

\section{Results}

\subsection{Questionnaire}

The questionnaire submitted to the users was of a thematic nature, divided into three parts, and aimed at incorporating personal data, user experience (UX), and comprehension information.

\subsubsection{Personal Data}

At the time the questionnaire was submitted $29 \%$ of the users trained between 2 and $6 \mathrm{~h}$ a week, while only $14 \%$ of them engaged into physical activity for more than $6 \mathrm{~h}$ a week. These activities took mainly place outdoor, followed by gyms and homes. $71 \%$ of the subjects were used to monitor their physical activity through apps or other devices, while the remaining $29 \%$ preferred not to use any monitoring devices and virtual trainers. Twenty users out of 21 were considered "novices" (as they had never used a rowing machine to perform physical activity), while one user was considered "competent". 


\subsubsection{User Experience}

The $24 \%$ of users perceived a mental request of 5 (on a scale of 1 to 10 where 1 is the lowest level and 10 the highest level) while interacting with the integrated interface during training. Only 10\% sensed a mental request of 10 .

Data are similar in regards to physical request: $24 \%$ of users detected an request of 5 during the interaction with the machine and only a 5\% has detected a level of 10 .

Regarding the physical and mental requested to reach the personal level of performance during the interaction with the rower, $29 \%$ of the users recorded a level equal to 6 and only 5\% a level equal to 10 (Fig. 2).

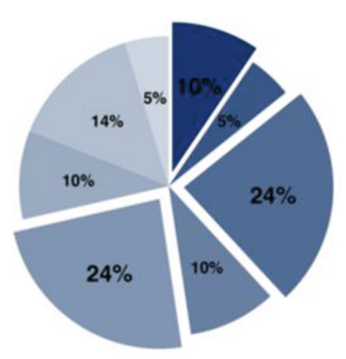

Mental request

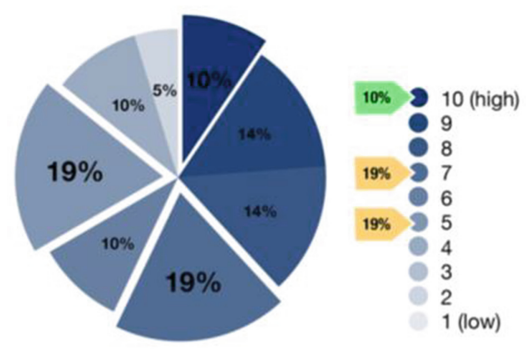

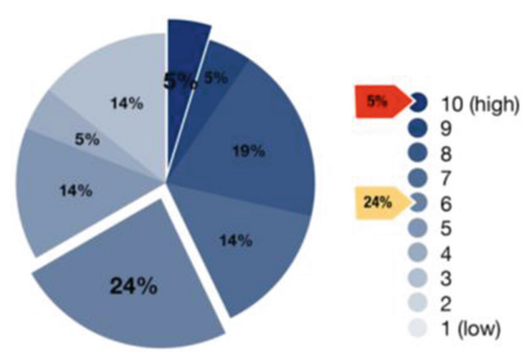

Physical request

\section{Performance level}

Fig. 2. Rower User Experience. Mental request, physical request and performance level charts.

Regarding the "performance level", which express how much each user believes to have been successful in completing the assigned task, 19\% of users recorded a level of 5 and 7 while $10 \%$ had difficulty in bringing the task to completion. Most users have not experienced high levels of frustration while interacting with the product. With regard to the SkillRow app user experience, most users found the application easy to use, as the application itself guided users to achieve their goals. 5\% of the users perceived a mental request of $1,24 \%$ a level of 5 and $10 \%$ equal to 10 . Only $19 \%$ recorded a level of physical exertion of 5 and 9 . As shown in the chart, majority of the users did not register high levels of frustration (Fig. 3). 


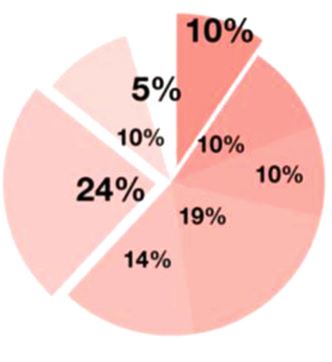

Mental request

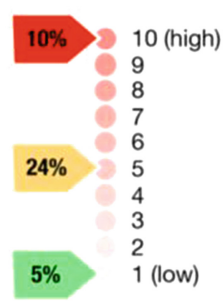

$19 \%$

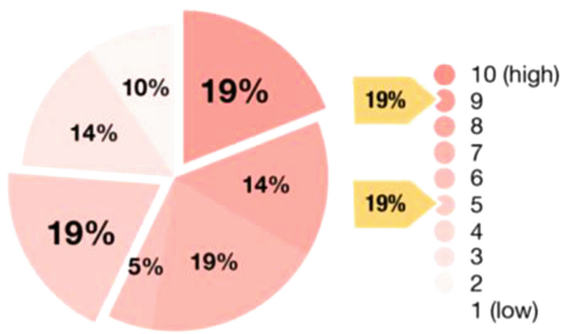

Physical request

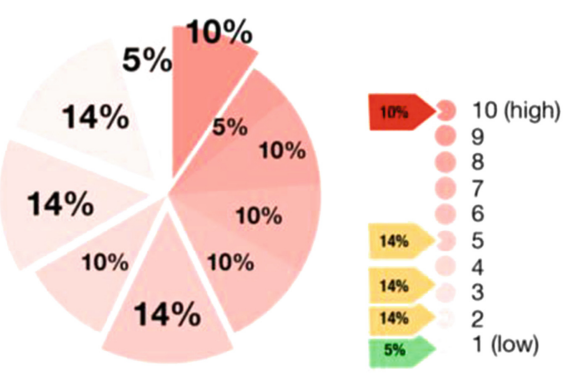

\section{Performance level}

Fig. 3. App Skillrow User Experience. Mental request, physical request and performance level charts

The physical request to interact with the application means aspects like visibility and reachability of the smartphone during the rowing exercise.

\subsubsection{Comprehension}

A significant portion of users did not experience difficulties in understanding how to use the rowing machine, how to turn it on and off, and how to regulate the physical activity intensity. As for the parameters displayed on the rowing machine's screen, almost all users recognize and understood the meaning of the icon and the numerical parameter of the time, distance and Kcal consumed. The majority of users also recognized the icon and understood the numeric parameter relative to both the $500 \mathrm{~m}$ split time and the $\mathrm{W}$ (power) generated.

On the other hand, $57 \%$ of users did not understand the numerical parameter, nor they recognized the icon, relative to the strokes per minute (spm). Majority of the users also had trouble understanding and/or recognizing the information relative to resistance level, AVG, DRAG, REPS.

The last section of the questionnaire covered the understanding of the Skillrow application. $76 \%$ of users recognized the icons and their meaning, but $62 \%$ of the 
interviewed users declared overall difficulties in using of the app. Finally, 38\% of users consider the skillrow application to be fairly comprehensible.

\subsubsection{Overall UX Evaluation and Net Promoter Score}

As showed in Overall User Experience chart, $81 \%$ of users assessed the overall product user experience positively ( $5 \%$ a level of $10,24 \%$ a level of $9,38 \%$ a level of $8,14 \%$ a level of 7), while $19 \%$ of users assessed it as sufficient (14\% a level of 6 and $5 \%$ a level of 5). In the other chart, Net promote score, is clear how the $53 \%$ of users highly recommend the use of Skillrow to other people, while the rest of users suggest the use of the product with a varying level from 7 to 5 (Fig. 4).

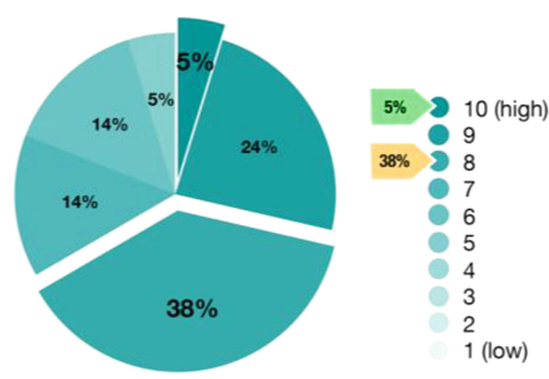

Overall User Experience

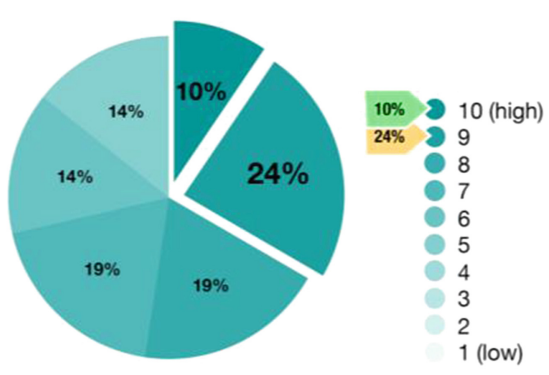

Net Promote Score (NPS)

Fig. 4. Overall User Experience and Net Promoter Score (NPS) charts

\subsection{Brainstorming and Focus Group}

This section highlighted that the problems experienced by the users were mainly due to the limited usability of the SkillRow application interface. In fact, most information could be understood only by advanced users. Some issues also arose with the SkillRow itself and with its interface. In fact, some users did not consider some of the information displayed on the screen or they misinterpreted them, some had trouble with the regulation of fundamentals components such as the pedals or the dumper settings (users tried to push or press the wheel instead of rotating it).

\subsection{Task Analysis}

What emerged from the two Task Analysis relative to the interaction with the SkillRow application interface, is that the application itself offers two types of interaction: press and scroll. The issues while using it were due to:

- Difficulty in visualizing the available exercises and in understanding them;

- Poor access intuitiveness to sub-menus;

- Difficulty in setting some parameters before physical activity;

- Difficulty in understanding certain specific acronyms and graphs relative to physical activity results. 


\subsection{Personas and Scenario-Based Design}

In light of the critical issues emerged from the questionnaires, the Brainstorming and Focus Group, and the Task Analysis, the Personas and the Scenarios were designed. Thanks to this technique it was possible to define possible implementations for the rowing machine, the rower interface and the app so that they can be easy to use also for those with limited or little experience with this type of products and activities. Figure 5 represents only some of the Personas and the new Scenarios designed during the workshop.

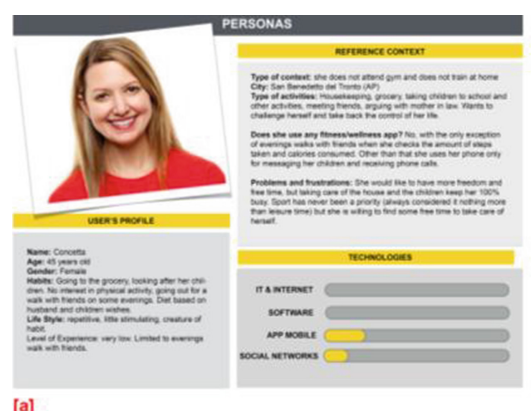

[a]

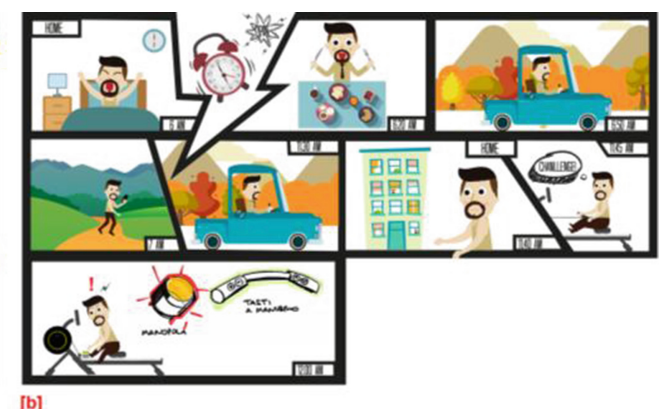

[b]

Fig. 5. Personas (a) and Scenario-based design (b)

\section{Conclusions}

The paper proposes some methodological implications in the evaluation of usability and User Experience (UX) with the new SkillRow rowing machine. The empirical approach allowed us to determine criticalities and difficulties in addition to gather thoughts and suggestions from a segment of users representative of the target. These methodologies are also useful for improving the product usability, which enhances pleasure, satisfaction and user experience. In order to do that, it was necessary to adopt a Human-centered approach, aimed at indirectly or directly involving the user, as a partner of inestimable value, during all phases of the project. Furthermore, the Ergonomics for design and its methods offer many opportunities for intervention, thus allowing to outline new usage scenarios and new services-products.

\section{References}

1. World Health Organization: Global Recommendations on Physical Activity for Health. WHO, Geneva (2010)

2. World Health Organization: Health and Development Through Physical Activity and Sport. WHO, Geneva (2003)

3. Tosi, F., Rinaldi, A., Busciantella Ricci, D., Pistolesi M., Brischetto A.: Ergonomics evaluation and redesign of workstation to prototyping of luxury garments. In: XI Congresso nazionale SIE 2016, Napoli (2016) 
4. Biscarini, A.: Measurement of power in selectorized strength-training equipment. J. Appl. Biomech. 28(3), 229-241 (2012)

5. Carraro, A., Gobbi, E., Ferri, I., Benvenuti, P., Zanuso, S.: Enjoyment perception during exercise with aerobic machines. Percept. Mot. Skills 119(1), 146-155 (2014)

6. Reilly, T., Lees, A.: Exercise and sports equipment: some ergonomics aspects. Appl. Ergon. 15(4), 259-279 (1984)

7. UNI 11377-1:2010: Usabilità dei prodotti industriali, parte 1, Principi generali, termini e definizioni (2010)

8. ISO 9241-210:2010: Ergonomics of human-system interaction, part 210: human-centred design for interactive systems (2010)

9. Nielsen, J.: Usability Engineering. Morgan Kaufmann, Elsevier, Burlington (1994)

10. Polillo, R.: Facile da utilizzare. Una moderna introduzione generale all'ingegneria dell'usabilità, Apogeo Education, Milan (2010)

11. Tosi, F.: Ergonomia e progetto. Franco Angeli, Milan (2006)

12. Hollnagel, E., Woods, D.D.: Joint Cognitive Systems: Foundations of Cognitive System Engineering. CRC Press, Boca Raton (2005)

13. Triberti, S., Brivio, E.: User Experience, Psicologia degli oggetti, degli utenti e dei contesti d'uso, Apogeo Education, Maggioli Editore, Santarcangelo di Romagna (2016)

14. Stanton, N.A., Young, M.S., Harvey, C.: Guide to Methodology in Ergonomics. Taylor and Francis, Oxford (2014)

15. Hacksos, J.T., Redish, J.C.: User and Task Analysis for Interface Design. Wiley, New York (1998)

16. Rogers, Y., Sharp, H., Preece, J.: Interaction Design: Beyond Human Computer Interaction, 3rd edn. Wiley, Chichester (2011)

17. Ericsson, K.A., Simon, H.A.: Protocol Analysis: Verbal Reports as Data. MIT Press, Cambridge (1985)

18. Hartson, R., Pyla, P.S.: The UX Book: Process and Guidelines for Ensuring a Quality User Experience, pp. 280-284. Elsevier, Amsterdam (2012)

19. Cooper, L., Baber, C.: Focus Groups in Handbook of Human Factors and Ergonomics Methods. CRC Press, Boca Raton (2005)

20. Pruitt, J., Grudin, J.: Personas: practice and theory. In: Proceedings of the 2003 Conference on Designing for User Experiences, pp. 1-15. ACM, June 2003

21. Rosson, M.B., Carroll, J.M.: Usability Engineering: Scenario-Based Development of Human-Computer Interaction. Morgan Kaufmann, San Francisco (2002)

22. UNI 11377-2:2010: Usabilità dei prodotti industriali, parte 2, Metodi e strumenti di intervento (2010)

23. NASA: Task Load Index (TLX): Paper and Pencil Version, Moffett Field CA: NASA Ames Research Center, Aerospace Human Factors Research Division (1986)

24. Hart, S.G., Stavelend, L.E.: Development of NASA-TLX (Task Load Index): results of empirical and theoretical research. In: Advances in Psychology, North-Holland, vol. 52, pp. 139-183 (1998) 